Jurnal Ilmu Dan Teknologi Kesehatan

Vol 7, No 1, September 2019,

ISSN: 2338-9095 (Print)

ISSN: 2338-9109 (online)

\title{
Nyeri Lutut Berpengaruh terhadap Kemampuan Fungsi Fisik Pasien dengan Osteoarthritis Lutut
}

\author{
Sahrudi $^{1}$, Riri Maria ${ }^{2}$, Tuti Herawati ${ }^{2}$ \\ ${ }^{1}$ Sekolah Tinggi Ilmu Kesehatan Abdi Nusantara Jakarta, ${ }^{2}$ Universitas Indonesia \\ Email :sahrudi@yahoo.com
}

\author{
Artikel history \\ Dikirim, Jun $25^{\text {th }}, 2019$ \\ Ditinjau, July $27^{\text {th }}, 2019$ \\ Diterima, September $5^{\text {th }}, 2019$
}

\begin{abstract}
Osteoarthritis (OA) genu can cause a decrease in the ability of physical function that involves movement of the knee joint during the activity. The purpose of this study was to analyze the factors that affect the physical function ability of patients with OA genu. This is a cross sectional study with 96 samples. Bivariate analysis showed gender factor $(p=0,029)$ and knee pain $(p=0,011)$ significantly correlated to the ability of physical function of patients with OA genu; while other factors respectively age $(p=0.616)$, motivation $(p=0.074)$, body mass index $(p=0.833)$, knowledge $(p=0.642)$, and disease comorbidity $(p=0.604)$ were not associated to the physical function ability of patients with $O A$ genus. Multivariate analysis showed that knee pain was the most influential factor (dominant) affect the ability of physical function of patients with OA genu ( $p=0,035 ; \beta=0,217)$.
\end{abstract}

Keywords: Ability of physical function; activity; osteoarthritis; knee pain

\begin{abstract}
ABSTRAK
Osteoarthritis (OA) pada lutut dapat menimbulkan penurunan terhadap kemampuan fungsi fisik terutama yang melibatkan pergerakan sendi lutut saat beraktivitas. Penelitian ini bertujuan menganalisis faktor - faktor yang mempengaruhi kemampuan fungsi fisik pasien dengan OA pada lutut. Desain penelitian ini adalah deskriptif analitik melalui pendektan cross sectional dengan 96 sampel. Analisis bivariat menunjukan faktor jenis kelamin $(p=0,029)$ dan nyeri lutut $(p=0,011)$ berhubungan secara bermakna dengan penurunan kemampuan fungsi fisik pasien dengan OA pada lutut; sementara faktor usia $(p=0,198)$, dukungan keluarga $(p=0,648)$, lama penyakit $(p=0,616)$, motivasi $(p=0,074)$, indeks masa tubuh $(p=0,833)$, pengetahuan $(p=0,642)$, dan penyakit komorbiditas $(p=0,604)$ tidak berhubungan dengan kemampuan fungsi fisik pasien dengan OA pada lutut. Analisis multivariat menunjukan bahwa nyeri lutut merupakan faktor yang sangat berpengaruh (dominan) terhadap kemampuan fungsi fisik pasien OA pada lutut $(p=0,035 ; \beta=0,217)$.
\end{abstract}

Kata kunci: Kemampuan fungsi fisik; aktivitas; osteoarthritis; nyeri lutut 


\section{PENDAHULUAN}

Osteoarthritis (OA) adalah erosi progresif pada artikular tulang rawan (Michael, Schluter-Brust, \& Eysel, 2010). Prevalensi OA secara global 9,6\% mengenai pria dan sebanyak $18 \%$ pada wanita dengan usia masing-masing lebih dari 60 tahun (WHO, 2017). OA dapat terjadi pada sendi pergelangan tangan, panggul dan lutut. Studi cross-sectional oleh YefiL, Hepguler, Ozturk, Capaci, and YesiL, (2013) menemukan besar angka kejadian OA pada sendi daerah lutut sebesar $20,9 \%$, tangan $2,8 \%$ dan panggul sebesar 1\%. Dampak OA pada lutut dapat menyebabkan gangguan fungsional yaitu gangguan kemampuan dalam melakukan aktivitas (Davison, Ioannidis, Maly, Adachi, \& Beattie, 2016). Sebuah penelitian yang dilakukan (Ganasegeran et al., 2014) pada pasien dengan osteoarthritis pada lutut didapatkan 53\% memiliki tingkat pengetahuan yang kurang dalam memahami tentang penyakitnya. Keadaan ini dapat mempengaruhi kemampuan fungsi fisik pasien dan berdampak pada program perawatan serta pengobatan yang diberikan oleh tenaga kesehatan.

Faktor usia berpengaruh juga terhadap kemampuan fungsi fisik pasien OA lutut.
Dengan bertambahnya usia, terjadi perubahan pada otot rangka sehingga jumlah dan intensitas aktivitas pasien menjadi berkurang (Moschny, Platen, Klaaben, Trampisch, \& Hinrichs, 2011). Penurunan kemampuan fungsi fisik juga berhubungan dengan faktor penyakit komorbiditas. Penyakit komorbiditas merupakan penyakit yang terdiagnosis secara bersamaan pada orang yang sama, dimana masing-masing diagnosis penyakit berkontribusi. Komorbiditas dapat menimbulkan efek negatif terhadap status kesehatan yaitu fungsi fisik dan kognitif yang dapat melebihi jumlah efek penyakit tunggal (Rozzini et al., 2002). Studi menunjukan bahwa pasien OA lutut yang mengalami hipertensi memiliki kecendrungan tidak aktif dalam bergerak dan berpartisipasi dalam kegiatan sosial dimasyarakat, pasien OA lutut dengan diabetes juga kurang aktif daripada mereka yang tidak terkena penyakit diabetes (Wood et al., 2007).

Berdasarkan studi kohort di Amerika, $42 \%$ responden OA lutut dengan diabetes tidak aktif dibandingkan dengan $27 \%$ dari responden tanpa diabetes (Vnmcken et al., 2004). Faktor yang mempengaruhi kemampuan fungsi fisik pasien OA pada lutut berikutnya adalah jenis kelamin. 
Studi oleh Loprinzi and Cardinal (2012) menunjukan bahwa yang aktif dalam melakukan pergerakan rata-rata lebih tinggi pada laki-laki bila dibandingkan dengan wanita. Penelitian Caspersen et al. (2000) juga menemukan bahwa wanita dewasa (18 tahun atau lebih) memiliki prevalensi lebih tinggi (27\%) waktu luang untuk bergerak dari pada laki-laki (21\%). Penelitian Hanrungcharotorn, Pinyopasakul, and Pongthavornkamol (2017) pada pasien OA lutut di unit rawat jalan rumah sakit di Bangkok Thailand, menunjukan sebanyak $63,7 \%$ wanita mengalami aktivitas yang rendah. Sedangkan penelitian Groot, Bussmann, Stam, and Verhaar (2008) diperoleh hasil tidak terdapat pengaruh antara jenis kelamin dengan aktivitas fisik ( $p>0,05)$. Berbagai penelitian yang ada berupaya untuk mengetahui faktor-faktor yang mempengaruhi kemampuan fungsi fisik pasien OA lutut. Meskipun demikian, terdapat beberapa perbedaan karakteristik antara penelitian ini dengan penelitian lainnya. Beragamnya karakteristik responden mungkin akan menunjukan hasil yang berbeda dengan penelitian sebelumnya.

\section{METODE}

Penelitian melibatkan 96 responden. Desain yang digunakan adalah cross- sectional dengan consecutive sampling. Kriteria inklusi adalah Pasien yang terdiagnosis OA pada lutut, pasien dapat membaca dan menulis serta bersedia menjadi responden. Penelitian ini dilaksanakan pada bulan Oktober hingga bulan November 2017 di poliklinik ortopedi Rumah Sakit Anna Medika Bekasi. Alat ukur yang digunakan adalah lembar isian karakteristik responden yang berisi usia, jenis kelamin, dan imt. Pengetahuan diukur dengan kuesioner Patient Knowledge Questionnaire Osteoarthritis (PKQ-OA), dukungan keluarga dinilai dengan kuesioner Family $A F G A R$, nyeri lutut di ukur dengan kuesioner Numeric Rating Scale (NRS), motivasi dengan kuesioner HMS-PA/ Health Motivation Scale in Physical Activities dan kemampuan fungsi fisik mengunakan kuesioner Western Ontario and McMaster Universities Osteoarthritis Index (WOMAC)- Physical Function Subscale. Analisis data pada penelitian ini menggunakan pearson correlation untuk mengetahui hubungan usia, dukungan keluarga, nyeri lutut, dan pengetahuan. Spearman correlation digunakan untuk mengetahui hubungan lamanya OA lutut dan motivasi. uji one way anova digunakan untuk mengetahui hubungan IMT. Uji t digunakan untuk mengetahui hubungan jenis kelamin dan penyakit 
komorbiditas terhadap kemampuan fungsi fisik. Analisis regresi linear digunakan untuk mengetahui faktor-faktor yang paling berpengaruh dan memprediksi kemampuan fungsi fisik.

\section{HASIL DAN PEMBAHASAN}

Hasil analisis pada tabel 1 menunjukan bahwa lebih dari sebagian responden berjenis kelamin perempuan sebanyak 75 responden $(78,1 \%)$. IMT responden sebagian besar adalah normal sebanyak 74 responden (77,7\%). Responden yang tidak memiliki penyakit komorbiditas sebanyak 70 responden $(72,9 \%)$.

Tabel 1. Distribusi Frekuensi Responden OA pada Lutut Berdasarkan Jenis Kelamin, IMT dan penyakit komorbiditas

\begin{tabular}{lcc}
\hline \multicolumn{1}{c}{ Variabel } & Frekuensi & Persentase (\%) \\
\hline Jenis Kelamin & & \\
$\quad$ Perempuan & 75 & 78.1 \\
$\quad$ Laki - Laki & 21 & 21.9 \\
\hline IMT & & \\
Kurus & 21 & 21.9 \\
Normal & 74 & 77.1 \\
$\quad$ Berat Badan Lebih & 1 & 1.0 \\
\hline Penyakit Komorbiditas & & \\
$\quad$ Tidak Ada & 70 & 72.9 \\
$\quad$ Ada & 26 & 27.1 \\
\hline
\end{tabular}

Tabel 2 memberikan gambaran usia, dukungan keluarga, nyeri lutut, motivasi, pengetahuan, lama penyakit dan kemampuan fungsi fisik. Pada penelitian ini didapatkan rerata usia responden adalah 58,52 tahun dengan standar deviasi 6,761. 95\% diyakini rerata usia responden berada di antara 57,15 tahun sampai dengan 59,89 tahun. Usia paling muda adalah 40 tahun sementara usia paling tua adalah 74 tahun. Dukungan keluarga menunjukkan rerata 6,95 dengan standar deviasi 1,843. Analisis menunjukkan bahwa 95\% diyakini rerata skor dukungan keluarga berada di antara 6,57 sampai dengan 7,32. Nilai skor terendah adalah 4 sedangkan skor tertinggi adalah 10. Nyeri lutut responden memiliki rerata nyeri lutut 5,05 dengan standar deviasi 1,155, diyakini bahwa $95 \%$ rerata berada di antara 4,82 sampai dengan 5,29. Skor nyeri lutut terendah adalah 3 sedangkan skor tertinggi adalah 8. Sementara itu, motivasi responden menunjukkan nilai tengah dengan skor motivasi responden adalah 19. Skor motivasi terendah 14, dan skor tertinggi adalah 27. Skor pengetahuan responden menunjukan nilai tengah adalah 
10. Skor pengetahuan terendah 3, rerata kemampuan fungsi fisik 36,41 sedangkan skor tertinggi adalah 22. dengan standar deviasi 4,723. Analisis Berikutnya skor lama penyakit responden menunjukan nilai tengah adalah 1 . Skor lama penyakit terendah 1 , sedangkan skor tertinggi adalah 5. Responden memiliki menunjukan diyakini bahwa $95 \%$ rerata berada di antara 35,45 sampai dengan 37,36. Nilai skor terendah 27 sedangkan skor tertinggi adalah 44.

Tabel 2. Distribusi Frekuensi Responden OA pada Lutut Berdasarkan Usia, dukungan keluarga, nyeri lutut, pengetahuan, motivasi, dan kemampuan fungsi fisik

\begin{tabular}{lccccc}
\hline \multicolumn{1}{c}{ Variabel } & Mean & Median & SD & Min - Maks & 95\% CI \\
\hline Usia & 58.52 & 59.50 & 6.761 & $40-74$ & $(57.15-59.89)$ \\
Dukungan keluarga & 6.95 & 7 & 1.843 & $4-10$ & $(6.57-7.32)$ \\
Nyeri Lutut & 5.05 & 5 & 1.155 & $3-8$ & $(4.82-5.29)$ \\
Motivasi & 18.99 & 19 & 1.803 & $14-27$ & $(18.62-19.36)$ \\
Pengetahuan & 9.75 & 10 & 2.587 & $3-22$ & $(9.23-10.27)$ \\
Lama Penyakit & 1.63 & 1 & 0.837 & $1-5$ & $(1.46-1.79)$ \\
Kemampuan Fungsi Fisik & 36.41 & 37 & 4.723 & $27-44$ & $(35.45-37.36)$ \\
\hline
\end{tabular}

Berdasarkan Tabel 3 didapatkan hasil analisis rata-rata kemampuan fungsi fisik responden perempuan adalah 36.96 dengan standar deviasi 4.431, sedangkan laki-laki rata-rata kemampuan fungsi fisiknya 34.43 dengan standar deviasi 5.297. Hasil uji statistik didapatkan nilai $p=0,029$, berarti pada alpha $5 \%$ terlihat ada pengaruh yang signifikan kemampuan fungsi fisik ratarata responden perempuan dengan responden laki-laki. Hasil analisis IMT pada tabel 3 didapatkan bahwa rata-rata kemampuan fungsi fisik responden yang memiliki IMT kategori kurus adalah 35.86 dengan standart deviasi 5.782, kemudian responden dengan IMT normal rata-rata kemampuan fungsi fisiknya 36.55 dengan standar deviasi 4.445 dan responden yang memiliki IMT kategori berat badan lebih adalah 37.00. Hasil uji statistik menunjukan nilai $p=0,833$, berarti pada alpha $5 \%$ terlihat tidak ada pengaruh yang signifikan kemampuan fungsi fisik ratarata responden dengan IMT kurus, normal dan berat badan lebih. Hasil analisis penyakit komorbiditas pada tabel 3. di dapatkan bahwa rata-rata kemampuan fungsi fisik responden yang memiliki penyakit komorbid adalah sebesar 36,04 dengan standar deviasi 3.862, sedangkan responden OA lutut yang tidak memiliki penyakit komorbid rata-rata kemampuan fungsi fisiknya adalah 36.54 dengan standar deviasi 5,024. Hasil uji statistik didapatkan nilai $p=0,644$, berarti pada alpha $5 \%$ terlihat tidak ada perbedaan 
yang signifikan kemampuan fungsi fisik rata-rata responden yang memiliki penyakit komorboditas dengan yang tidak memiliki penyakit komorbiditas. Kemudian hasil analisis pada tabel 4 menunjukan tidak ada hubungan yang signifikan antara usia dengan kemampuan fungsi fisik $(p=0,198)$. Sementara nyeri lutut dengan kemampuan fungsi fisik ada hubungan yang signifikan $(p=0,011)$, diperoleh nilai hubungan lemah $r=0,259$. Artinya semakin bertambah skor nyeri lutut maka semakin bertambah skor kemampuan fungsi fisik responden sehingga kemampuan fungsi fisiknya akan menurun. Hasil analisis pada tabel 4 juga menunjukkan bahwa tidak terdapat hubungan yang signifikan antara dukungan keluarga dengan kemampuan fungsi fisik ( $p=0,648)$. Tidak terdapat hubungan yang signifikan antara motivasi dengan kemampuan fungsi fisik responden $(\mathrm{p}=0,074)$. Kemudian tidak terdapat juga hubungan yang signifikan antara lama penyakit dengan kemampuan fungsi fisik responden $(\mathrm{p}=0,616)$. Hasil analisis juga menunjukan pada tabel 4 , tidak terdapat hubungan yang signifikan antara pengetahuan dengan kemampuan fungsi fisik responden $\quad(p=0,642)$.

Tabel 3. Hasil Analisis jenis kelamin, IMT dan penyakit komorbiditas dengan kemampuan fungsi fisik

\begin{tabular}{lccccc}
\hline \multicolumn{1}{c}{ Variabel } & $\boldsymbol{n}$ & Mean & $\boldsymbol{S D}$ & $\boldsymbol{t} / \boldsymbol{f}$ & $\boldsymbol{p}$ Value \\
\hline Jenis Kelamin & & & & & \\
Perempuan & 75 & 36.96 & 4.431 & 2.215 & 0.029 \\
Laki - laki & 21 & 34.43 & 5.297 & & \\
\hline IMT & 21 & 35.86 & 5.782 & 0.183 & 0.833 \\
Kurus & 74 & 36.55 & 4.445 & & \\
Normal & 1 & 37.00 & - & & \\
Berat Badan Lebih & & & & & \\
Penyakit Komorbiditas & 26 & 36,04 & 3,862 & 0,463 & 0,644 \\
Ada & 70 & 36,54 & 5,024 & & \\
Tidak Ada & & & & & \\
\hline
\end{tabular}

Tabel 4. Hasil Analisis usia, nyeri lutut, dukungan keluarga, motivasi, lama penyakit OA, dan pengetahuan dengan kemampuan fungsi fisik

\begin{tabular}{lcc}
\hline \multicolumn{1}{c}{ Variabel } & $\boldsymbol{p}$ value & $\mathbf{r}$ \\
\hline Usia & 0.198 & 0.132 \\
Nyeri lutut & $0.011^{* *}$ & 0.259 \\
Dukungan Keluarga & 0.648 & -0.047 \\
Motivasi & 0.074 & -0.183 \\
Lama penyakit OA & 0.616 & 0.052 \\
Pengetahuan & 0.642 & -0.048 \\
\hline
\end{tabular}


Setelah melalui analisis regresi linier berganda didapatkan satu faktor yang dominan berpengaruh terhadap kemampuan fungsi fisik pasien OA pada lutut, yaitu nyeri lutut. Hasil akhir pemodelan multivariat dapat dilihat pada tabel 5. Variabel yang dominan mempengaruhi kemampuan fungsi fisik secara bermakna adalah nyeri lutut $(p=0,035)$ dan dengan nilai $\beta \quad 0,217$. Kekuatan hubungan positif dan hubungan lemah $r=0.307$. Variabel jenis kelamin dan nyeri lutut dapat menjelaskan variabel kemampuan fungsi fisik pasien osteoarthritis pada lutut sebesar 9,4\%. Persamaan regresi yang diperoleh adalah Kemampuan fungsi fisik $=32,342-1,931$ (jenis kelamin) $+0,888$ (nyeri lutut). Interpretasi persamaan regresi yaitu jenis kelamin laki-laki akan memiliki kemampuan fungsi fisik lebih baik sebesar 1,931 di bandingkan perempuan setelah dikontrol oleh variabel nyeri lutut. Sementara setiap kenaikan skor nyeri lutut 1 point, akan mengakibatkan penurunan kemampuan fungsi fisik sebesar 0,888 setelah dikontrol oleh variabel jenis kelamin.

Tabel 5. Model Analisis Regresi Linier Berganda

\begin{tabular}{lllllllll}
\hline Variabel & Koefisien & Beta & $\boldsymbol{T}$ & $\boldsymbol{P}$ Value & 95 \% CI & $\boldsymbol{r}$ & $\boldsymbol{R}^{\mathbf{2}}$ \\
\hline Konstanta & 32.342 & - & 14.526 & 0.001 & 27.921 & 36.764 & & \\
Jenis kelamin & -1.931 & -0.170 & -1.670 & 0.098 & -4.228 & 0.366 & 0.307 & 0.094 \\
Nyeri lutut & 0.888 & 0.217 & 2.134 & $0.035^{* *}$ & 0.062 & 1.714 & & \\
\hline **signifikan & & & & & & & &
\end{tabular}

\section{SIMPULAN}

Hasil analisis menunjukan bahwa nyeri lutut pada pasien yang mengalami OA pada lutut sangat besar pengaruhnya (dominan) terhadap penurunan kemampuan fungsi fisik pasien. Perawat dalam hal ini diharapkan dapat memberikan pendidikan kesehatan terhadap pasien dalam manajemen nyeri sehingga pasien mampu dalam meningkatkan kemampuan fungsi fisiknya.

\section{UCAPAN TERIMA KASIH}

Terima kasih kepada semua pihak yang telah berperan untuk kelancaran dan kesuksesan dalam penelitian ini.

\section{DAFTAR RUJUKAN}

Caspersen, Pereira, \& Curran. 2000. Changes in physical activity patterns in the United States, by sex and cross-sectional age. Med Sci Sports Exerc, 32(9), 1601-1609. https://doi.org/10.1097/00005768200009000-00013

Davison, M. J., Ioannidis, G., Maly, M. R., Adachi, J. D., \& Beattie, K. A. 2016. Intermittent and constant pain and physical function or performance in men and women with knee 
osteoarthritis: data from the osteoarthritis initiative, 371-379. https://doi.org/10.1007/s10067-014$2810-0$

Ganasegeran, K., Menke, J. M., Challakere Ramaswamy, V. M., Abdul Manaf, R., Alabsi, A. M., \& Al-Dubai, S. A. R. 2014. Level and determinants of knowledge of symptomatic knee osteoarthritis among railway workers in Malaysia. doi.org/10.1155/2014/370273

Groot, I. B., Bussmann, J. B., Stam, H. J., \& Verhaar, J. A. N. 2008. Actual everyday physical activity in patients with end-stage hip or knee osteoarthritis compared with healthy controls. Osteoarthritis and Cartilage. 16(4), 436-442. https://doi.org/10.1016/j.joca.2007.0 8.010

Hanrungcharotorn, U., Pinyopasakul, W., \& Pongthavornkamol, K. 2017. Factors Influencing Physical Activity among Women with Osteoarthritis of the Knee. Pacific Rim Int J Nurs, (1), 5-17.

Loprinzi, P. D., \& Cardinal, B. J. 2012. Interrelationships among physical activity, depression, homocysteine, and metabolic syndrome with special considerations by sex. Preventive Medicine, 54(6), 388-392. https://doi.org/10.1016/j.ypmed.2012 .03 .016

Michael, J. W., Schluter-Brust, K. U., \& Eysel, P. 2010. The epidemiology, etiology, diagnosis, and treatment of osteoarthritis of the knee. Dtsch Arztebl Int, 107(9), 152-162. https://doi.org/10.3238/arztebl.2010.
0152

Moschny, A., Platen, P., Klaaben, R., Trampisch, U., \& Hinrichs, T. 2011. Barriers to physical activity in older adults in Germany: a cross-sectional study. International Journal of Behavioral Nutrition and Physical Activity. $\quad 8(1), \quad 121$. https://doi.org/10.1186/1479-5868-8121

Rozzini, R., Frisoni, G. B., Ferrucci, L., Barbisoni, P., Sabatini, T., Ranieri, P., Trabucchi, M. 2002. Geriatric Index of Comorbidity: Validation and comparison with other measures of comorbidity. Age and Ageing. 31(4), 277-285. https://doi.org/10.1093/ageing/31.4.2 77

Vnmcken, C. Van, Bopp, C. M., Reis, J. P., Ms, K. D. D., Kirtland, K. A., \& Ainsworth, B. E. 2004. The Prevalence of Leisure-Time Physical Activity Among Diabetics in South Carolina, 97(2), 141-145.

Wood, J. E., Barrows, J. G., Freis, E. D., Gifford, R. W., Kirkendall, W. M., Lee, R., Abrams, H. 2007. Primary prevention of hypertension. The Journal of the American Osteopathic Association.

YefiL, H., Hepguler, S., Ozturk, C., Capaci, K., \& YesiL, M. 2013. Prevalence of symptomatic knee, hand and hip osteoarthritis among individuals 40 years or older: A study conducted in izmir city. Acta Orthopaedica et Traumatologica Turcica, 47(4), 231-235. https://doi.org/10.3944/aott.2013.273 1 